\title{
EDUCAÇÃO DOS ESTUDANTES SURDOS E LEGISLAÇÃO LINGUISTICA: UMA ANÁLISE FOUCAULTIANA SOBRE DISPOSITIVOS DE SEGURANÇA ${ }^{1}$
}

Nelson Dias ${ }^{2}$ https://orcid.org/0000-0002-1256-8088

Karine Albuquerque de Negreiros ${ }^{3}$ https://orcid.org/0000-0001-7849-1151

RESUMO: Nas últimas décadas, a legislação brasileira voltou seu olhar para pessoas surdas, buscando garantir acessibilidade, direitos linguísticos, educacionais e promoção de saúde. Contudo, existem pontos sutis nesses documentos que identificamos como sendo dispositivos de segurança, um conceito proposto por Foucault, como uma forma de manutenção do controle desses sujeitos. Dessa forma, objetivamos analisar a lei 10.436 de 24 de abril de 2002 e no decreto 5626 de 22 de dezembro de 2005 a fim de elencar os dispositivos de segurança neles inseridos. As discussões estão pautadas no referencial teórico de Foucault (2008), recorrendo aos conceitos de dispositivos de segurança, assujeitamento e relações de poder, por ele desenvolvidos. Elencamos, depois de uma leitura atenta e respaldados no aporte teórico proposto, sete dispositivos de segurança nos documentos analisados. Conclui-se que esses dispositivos refletem diretamente na oferta de uma educação bilíngue para estudantes surdos e nas aplicações em políticas públicas como garantia desses direitos.

PALAVRAS-CHAVE: Dispositivo de segurança, Libras, relação de poder

\section{EDUCATION OF DEAF STUDENTS AND LINGUISTIC LEGISLATION: A FOUCAULTIANA ANALYSIS ON SAFETY DEVICES}

ABSTRACT: In recent decades, Brazilian legislation has turned its gaze to deaf people, seeking to guarantee accessibility, linguistic, educational and health promotion rights. However, there are subtle points in these documents that we identify as security devices, a concept proposed by Foucault, as a way of maintaining control

\footnotetext{
${ }^{1} \mathrm{O}$ presente trabalho foi realizado com apoio da Universidade Federal de Mato Grosso do Sul - UFMS/ MEC - Brasil.

${ }^{2}$ Doutorando em Ensino de Ciências - INFI/ Universidade Federal de Mato Grosso do Sul - UFMS. Mestrado em Educação - FAED/UFMS. Professor de Libras - UFMS. nelsonufms@hotmail.com

${ }^{3}$ Doutoranda em Educação - FAED/ Universidade Federal de Mato Grosso do Sul - UFMS. Mestrado em Letras - UEMS. Professora de Libras - UFMS. karine.albuquerque@ufms.br
} 
of these subjects. Thus, we aim to analyze Law 10,436 of April 24, 2002 and Decree 5626 of December 22, 2005 in order to list the security devices inserted in them. The discussions are based on the theoretical framework of Foucault (2008), using the concepts of security devices, subjection and power relations, developed by him. We list, after a careful reading and supported by the proposed theoretical contribution, seven security devices in the analyzed documents. It is concluded that these devices directly reflect the offer of bilingual education for deaf students and the applications in public policies as a guarantee of these rights.

KEYWORDS: Safety device, Libras, power relationship

\section{EDUCACIÓN DE ESTUDIANTES SORDOS Y LEGISLACIÓN LINGÜÍSTICA: UN ANÁLISIS FOUCAULTIANO SOBRE DISPOSITIVOS DE SEGURIDAD}

RESUMEN: En las últimas décadas, la legislación brasileña ha dirigido su atención a las personas sordas, buscando garantizar la accesibilidad, los derechos lingüísticos, educativos y de promoción de la salud. Sin embargo, hay puntos sutiles en estos documentos que identificamos como dispositivos de seguridad, un concepto propuesto por Foucault, como una forma de mantener el control de estos temas. En consecuencia, nuestro objetivo es analizar la Ley 10.436 del 24 de abril de 2002 y el Decreto 5626 del 22 de diciembre de 2005 para enumerar los dispositivos de seguridad insertados en ellos. Las discusiones se basan en el marco teórico de Foucault (2008), utilizando los conceptos de dispositivos de seguridad, sujeción y relaciones de poder, desarrollados por él. Enumeramos, después de una lectura cuidadosa y apoyados por la contribución teórica propuesta, siete dispositivos de seguridad en los documentos analizados. Se concluye que estos dispositivos reflejan directamente la oferta de una educación bilingüe para estudiantes sordos y las aplicaciones en políticas públicas como garantía de estos derechos.

PALABRAS CLAVE: Dispositivo de seguridade, Libras, relaciones de poder

\section{Introdução}

A educação dos surdos desde seus primórdios foi permeada pelas relações de poder em seus mais diversos contextos. Passando pelas longas terapias de fala até chegar ao reconhecimento da Língua Brasileira de Sinais - Libras, da inclusão escolar à promessa da educação bilíngue, encontramos práticas pedagógicas subsidiadas pelos dispositivos legais, que nos provam existir um distanciamento do que é almejado pela comunidade surda. Demonstrando uma 
evidente forma de poder e controle que estão presentes na própria legislação.

Sabemos que os surdos são em gênese uma minoria, que por sua vez, reflete na desvalorização da sua língua bem como nos processos educativos. Essa configuração em si traz a carga, levantada pela comunidade surda, de sempre lutarem para não serem assujeitados por uma sociedade com práticas totalizantes. Dessa maneira, podemos inserir que foi por meio de formas de poder disfarçadas de preocupações com a saúde auditiva que por muitos anos submeteram os surdos a perda de sua subjetividade, sob práticas controladoras de disciplina e controle.

Há apenas 20 anos começou a se discutir sobre surdez e as relações de poderes e saberes que envolvem especificidades linguísticas e culturais dos surdos. Durante esses anos, a comunidade surda obteve algumas importantes conquistas que, ao avaliarmos mediante a algumas interfaces com a sociedade atual, é possível constatar avanços significativos em relação ao reconhecimento político. Conseguiram, com suas lutas e movimentos, alcançar os discursos oficiais e, assim a legislação, o que se representa uma mudança considerável. Contudo, são de fato mudanças significativas o suficiente para equilibrar a balança das relações de força que instituíram o poder?

Em meio a essa discussão e indagação que surge a motivação do presente artigo. Nesse sentido, objetivamos analisar essas legislações a fim de elencar dispositivos de segurança que nelas estão inseridos, o que de acordo com Foucault (2008) servem, em uma dada relação de poder, manter o controle de um determinado grupo, no caso em questão os sujeitos surdos.

Desse modo, fundamentamos a discussão a partir do conceito de dispositivo de segurança proposto por Foucault (2008). Fizemos uma breve descrição da metodologia empregada, elencamos sete dispositivos de segurança que encontramos na lei 10.436/02 e no decreto 5.626/05. Encerramos a discussão com os reflexos de tais dispositivos para a educação de surdos no Brasil, considerando as relações de poder descritas nos documentos e vivenciadas no espaço escolar.

\section{Metodologia}

Essa é uma pesquisa qualitativa de análise documental. Foram selecionadas as legislações que tratam sobre o direito linguístico dos sujeitos surdos: lei da acessibilidade no 10.098 de 19 de dezembro de 2000; Lei 10.436/02 de 24 de Abril 2002 que oficializa a língua de sinais; Decreto 5626 de 22 de dezembro de 2005 que regulamenta o uso e a difusão da Libras; lei 12.319 
de 1 de setembro de 2010 que regulamenta a profissão do intérprete. Essas leis foram selecionadas para uma leitura que Bardin (2011, p.126) chama de leitura flutuante que "consiste em estabelecer contato com os documentos a analisar e conhecer o texto. [...] Pouco a pouco, a leitura vai se tornando mais precisa, em função das hipóteses emergentes".

A partir dessa leitura realizamos a escolha dos documentos definindo o corpus da pesquisa. Bardin (2011) explica que o corpus representa um conjunto de documentos que serão submetidos a procedimentos analíticos. A escolha dos documentos se deu por regra de pertinência. Nesse sentido, foram escolhidos os documentos que mais tinham relação com o problema de pesquisa, no caso em questão a lei 10436/02 e o decreto 5626/05 pois essas tratam diretamente sobre o direito a educação dos surdos em relação a sua condição linguística. Nessa perspectiva, Bardin (2011, p. 128) esclarece que na regra de pertinência "os documentos retidos devem ser adequados enquanto fonte de informação, de modo a corresponderem ao objetivo que suscita a análise".

É nessa direção que se toma os aportes das pesquisas de Michel Foucault que fundamentam as características dos dispositivos de segurança e como esses dispositivos são usados para manter o controle de determinado grupo. Como se sabe, a surdez não foi um dos temas sobre os quais ele se debruçou, o que não nos impede de continuar pensando as questões sobre a educação de surdos a partir das contribuições foucaultianas.

\section{Dispositivos de Segurança}

Durante o período genealógico, ao estudar o sujeito, Foucault (1979) estabelece o conceito de dispositivo, que consiste em estratégias, táticas, que fabricam populações para atenderem determinada urgência histórica: a escola, a prisão, a família, são alguns desses dispositivos. A partir desse conceito, Foucault (2008) elenca alguns tipos de dispositivos, o de poder é um deles, a primeira vez que ele trata desse dispositivo é numa perspectiva disciplinar, em seu livro Vigiar e punir (2007). Entretanto, em trabalhos e cursos lecionados no Collége de France, após 1976, o pensador direciona o estudo do poder para outra perspectiva denominada biopoder, uma forma de exercício de poder sobre a vida, ou seja:

[...] o conjunto dos mecanismos pelos quais aquilo que, na espécie humana, constitui suas características biológicas fundamentais vai poder entrar numa política, numa estratégia política, 
numa estratégia geral de poder. Em outras palavras, como a sociedade, as sociedades ocidentais modernas, a partir do século XVIII, voltaram a levar em conta o fato biológico fundamental de que o ser humano constitui uma espécie humana. É em linhas gerais o que chamo, o que chamei, para lhe dar um nome, de biopoder (FOUCAULT, 2008, p. 8).

O biopoder é fundamento para Foucault abordar o dispositivo de segurança, que por sua vez trata-se de formas de manter um controle da sociedade em uma dada relação de poder. Todavia, precisamos entender que a concepção de segurança para o filósofo são formas que funcionam no interior de medidas de controle social. Segundo o autor os mecanismos de poder não são autogenéticos, o poder não se funda em si mesmo e não estabelece a partir de si. Foucault (2008) ainda afirma que não haveria relações familiares que não tivessem mecanismo de poder, não haveria, nem ao menos, relações sexuais se não houvesse relações de poder.

Nesse sentido, os mecanismos de poder são parte intrínseca em toda relação, e esses mecanismos têm "[...] O papel de mostrar quais são os efeitos do saber que são produzidos em nossa sociedade, pelas lutas, os choques e os combates que nela se desenrolam, e pelas táticas de poder que são os elementos dessas lutas" (FOUCAULT, 2008, p.5). Os dispositivos de segurança, por sua vez, fazem parte desse conjunto de táticas em que o grupo "controlado" legitima e dá ao grupo controlador um mecanismo de controle.

Nessa relação de grupos, Foucault (2008) chama a atenção para o que ele denomina de população flutuante: mendigos, delinquentes, vagabundos, ladrões, assassinos. Para o autor os mecanismos de controle agem para que esses grupos fiquem segregados à sociedade, não se trata de atingir um ponto de perfeição, mas de maximizar a boa circulação e minimizar a má circulação.

A pessoa com deficiência, por sua vez, caracteriza-se como parte do grupo de população flutuante, uma vez que fogem a "normalidade" padronizada por uma sociedade que nega as diferenças. Entretanto, a circulação de grupos distintos e suas relações é o que organiza uma sociedade. Nesse sentido, Foucault (2005) afirma que a ordem da sociedade só pode ser entendida pela tensão existente entre submissão e luta, ação e reação, dominados e dominantes.

Dessa forma, podemos pensar que a inclusão passa a ser um mecanismo de segurança, uma estratégia de poder estatal que absorve uma demanda social. Podemos citar como exemplo, a questão da escolarização de pessoas com deficiência, visando, institucionalizar uma política reguladora no estabe- 
lecimento de coesão social e de regulação de direitos e deveres.

O estado cujo poder se exerce de forma sutil, diluída por todas as relações sociais, a partir do investimento tanto de práticas disciplinares (sobre o corpo individual) quanto biopolíticas (sobre a totalidade da população), estabelece, na forma de lei, a relação que o surdo e a Língua de Sinais vão ter com a sociedade. Para entender essa relação passaremos a identificar dispositivos de segurança nas legislações e acessibilidade linguística dos surdos, como um mecanismo de controle de forma instituída.

\section{Dispositivos e legislação}

A lei que regulamenta a Libras como meio legal de comunicação e expressão no Brasil, nos permite entender que a língua teria sido oficializada, logo todos os direitos linguístico do Português seriam estendidos a elas, do mesmo modo que ela atenderia a qualquer cidadão brasileiro, seja ele surdo ou ouvinte. Entretanto, o que percebemos é que lei que a institui delimita quais são os usuários dessa língua:

Parágrafo único: Entende-se como Língua Brasileira de Sinais Libras a forma de comunicação e expressão, em que o sistema linguístico de natureza visual-motora, com estrutura gramatical própria, constituem um sistema linguístico de transmissão de ideias e fatos, oriundos de comunidades de pessoas surdas do Brasil (BRASIL, 2002, Art. 1).

Dispositivo 1 - A acessibilidade linguística limita-se a comunidade surda sendo eles: surdos sinalizados, tradutores intérpretes de libras, amigos e familiares que utilizam a língua de sinais. Assim, de uma forma velada se faz a inclusão da pessoa surda estabelecendo com quais pessoas devem se relacionar, ou seja, desobrigando a sociedade da consciência linguística para a acessibilidade da comunidade surda. A legitimidade foi dada apenas como uma margem aceitável da surdez no meio social. Como Foucault (2008) descreve, mantem a boa circulação mínima da população flutuante. Este é um dispositivo de segurança que limita o acesso das pessoas surdas a outras esferas da sociedade.

Aceitar a língua de sinais apenas para surdo e para aqueles que a queiram saber é o mesmo que impor uma definição de eles/nós, na qual 'eles', os surdos. não pertencem ao 'nós' e deve estar sempre em 'terceira pessoa' inclusive em políticas públicas linguísticas. A emergência das técnicas de normalização resulta no dispositivo para produzir discursos de normas. Não se trata 
de um saber judiciário, mas de um poder de normalização que se estabeleceu nas diferentes toda a sociedade.

Dispositivo 2 - Cabe considerarmos que na lei que regulamenta o uso da Língua de Sinais diz em seu parágrafo único que: "a Língua Brasileira de Sinais - Libras não poderá substituir a modalidade escrita da língua portuguesa" (BRASIL, 2002, Art. 1). Em uma demonstração claro de poder esse dispositivo evidencia que a Libras pode ser um meio legal de comunicação de uma parcela considerável da população no Brasil, contudo, não tem status de língua nacional, limitando assim, seu poder de uso e extensão e, retirando principalmente do governo responsabilidades quanto aos surdos.

O reconhecimento das línguas apenas como meio de comunicação e expressão e não como segunda língua oficial no país, é uma ação de admissão, aceitação e certificação de algo como verdadeiro. Dessa maneira, apenas concede permissão para o uso de difusão da Libras em alguns ambientes da sociedade. $\mathrm{O}$ artigo 13 da constituição federal diz "A língua portuguesa é o idioma oficial da República Federativa do Brasil". Dessa forma, caso não se altere a constituição, o Brasil continuará monolíngue.

Refletindo sobre a questão, percebemos a clareza desse dispositivo de segurança uma vez que ele reconhece a singularidade linguística dos surdos, no entanto, não toma medidas realmente cabíveis para atende-las e sim, toma posturas para controlar um grupo, aqui denominados de Flutuantes. Língua oficial é aquela que ocorre atos administrativos legais de uma nação, registros de um país. Desse modo, os surdos ficam a margem política, sofrendo uma regulação de seus direitos mais elementares. Por esse motivo, ficam sem acesso a diversas informação que não são traduzidas para a sua língua materna, enfraquecendo assim, sua participação efetiva na construção de uma sociedade justa e equitativa.

Outro dispositivo de segurança aparece ao analisarmos o artigo terceiro da lei 10436/02. Vale salientar que os sujeitos surdos são um grupo que possui uma língua com outra tipo de modalidade: visual-espacial. Nesse sentido, não enxergamos esse grupo como pessoas deficientes da linguagem, pois, a Libras possui todos os meios de expressão e comunicação com qualquer outra língua. Nessa ótica, o que precisamos pensar não são em tratamentos terapêuticos ou de reabilitação, mas sim, em possibilidade de ampliar a disseminação da língua em questão. Por esse motivo, elencamos o trecho da lei que inclui o próximo dispositivo a seguir:

Art. 3ำ As instituições públicas e empresas concessionárias de 
serviços públicos de assistência à saúde devem garantir atendimento e tratamento adequado aos portadores de deficiência auditiva, de acordo com as normas legais em vigor (BRASIL, 2002, art.3으).

Dispositivo 3 - A constituição federal garante a todos os cidadãos o direito a saúde, dessa forma, não haveria necessidade de um outro arranjo legal para garantir a saúde especificamente para pessoas surdas. No entanto, não há na lei nem do decreto que a regulamenta quais as formas desse atendimento específico. Outro aspecto relevante está no emprego do termo "tratamento adequado" colocado no artigo supracitado, o que pressupõe o entendimento de um tratamento em relação à surdez de forma terapêutica, ou seja, tratar a deficiência, colocando o sujeito surdo como um deficiente da linguagem, e não um cidadão merecedor dos direitos que garantam sua especificidade linguística.

Seguindo no próximo dispositivo, encontramos na lei, um artigo sobre os sistemas educacionais e a inclusão da Libras em cursos de formação. Ao analisarmos esse trecho, verificamos que a língua só se torna obrigatória em cursos de licenciaturas, fonoaudiologia e educação especial, conforme artigo a seguir:

\begin{abstract}
Art. 4o O sistema educacional federal e os sistemas educacionais estaduais, municipais e do Distrito Federal devem garantir a inclusão nos cursos de formação de Educação Especial, de Fonoaudiologia e de Magistério, em seus níveis médio e superior, do ensino da Língua Brasileira de Sinais - Libras, como parte integrante dos Parâmetros Curriculares Nacionais - PCNs conforme legislação vigente (BRASIL, 2002, Art. 4).
\end{abstract}

Dispositivos 4 - Esse dispositivo reduz a obrigatoriedade do ensino da língua de sinais apenas aos cursos de licenciaturas e fonoaudiologia. Entendemos em Foucault (1995) essa ação como sendo uma estratégia do dispositivo um dos "procedimentos utilizados num confronto para privar o adversário dos seus meios de combate e reduzi-lo a renunciar à luta" (FOUCAULT; 1995: 247). Incluir a Libras como disciplina curricular nos cursos de graduação deveria ser feito em todas as áreas. Existe aqui ainda um ponto convergente com outro dispositivo elencado, quando o decreto estabelece a formação de profissionais da saúde em Língua de Sinais, porém, não a inclui com disciplina nos cursos de enfermagem, fisioterapia, nutrição, medicina e todos os outros.

No entanto, algo que deve ser mencionado é a maneira como é ofertada a disciplina de Libras nas licenciaturas. Estas são oferecidas de forma 
semestral e não possuem disciplinas que deem continuidade ao ensino da Língua. Dessa maneira, esse é o formato que vem sendo usado como base da inclusão dos surdos na escola e na sociedade. Sabemos que o aprendizado de uma língua e cultura transcende a sala de aula, e ainda, a educação bilíngue, conforme discutido por Souza (2006) requer do docente fluência linguística e o uso justo das línguas envolvidas na escola de modo que ambas tenham o mesmo prestígio, uso e rigor.

Dispositivo 5 - Avançando um pouco mais sobre a legislação, analisemos o decreto que regulamenta a lei da Libras que reforça, de forma reducionista, a relação dessa língua apenas na educação. O capítulo terceiro leva o seguinte tema "formação dos professores e instrutores de libras", nos remetendo outra vez a ideia de que a relação da surdez se faz apenas com a educação. O referido capítulo trata da formação do profissional que ensinará a Libras e diz: "Parágrafo único: As pessoas surdas terão prioridade nos cursos de formação previstos no caput." (BRASIL, 2005, Art.3ㅇ). Esse dispositivo tenta, assim como o anterior, reduzir a atuação profissional das pessoas com surdez apenas para ensinar língua de sinais, não há prerrogativas legais de incentivo para o surdo que optar por outra área do conhecimento, nem ao menos essas outras áreas profissionalizantes são mencionadas na lei ou no decreto.

Ainda sobre esse dispositivo, percebemos ser comum os profissionais que trabalham com surdos reproduzir esse dispositivo de segurança. Trabalhamos em nome da inclusão, da acessibilidade, de uma sociedade igualitárias, entretanto, o que reforçamos é apenas uma margem aceitável da deficiência em nosso meio, como Foucault (2008) descreve na sua obra "Segurança, Território, População". Dessa forma, recorremos a esse discurso como um elemento que permite justificar e mascarar uma prática que, por sua vez, permanece inalterada, que isola e exclui determinado grupo.

Dispositivo 6 - Outro dispositivo observado está no artigo que versa sobre educação bilíngue dos surdos, no texto do decreto diz que: "escolas e classes de educação bilíngue, abertas a alunos surdos e ouvintes, com professores bilíngues, na educação infantil e nos anos iniciais do ensino fundamental" (BRASIL, 2005, Art. 22). A educação bilíngue, em escolas apropriadas, apenas será ofertada até os anos iniciais do ensino fundamental, uma vez que o texto segue discorrendo que nos anos finais e no ensino médio o ensino pode ser oferecido em escolas comuns da rede regular de ensino

Assim, o compromisso da oferta de escolas que atendam a necessi- 
dade linguística do aluno, com um ambiente linguístico favorável, por responsabilidade do governo federal, fica reduzido as séries iniciais e anos iniciais do ensino fundamental. A possibilidade da escolarização na rede regular de ensino para os demais anos permite ao grupo controlador delimitar onde e como, permitirá ao grupo controlado estudar, uma vez que oferece apenas a opção de escolas inclusivas resguardados pela mesma lei que aponta a possibilidade da educação bilíngue.

Vale ressaltar que nas diretrizes do ensino comum como opção, menciona que os docentes devem estar cientes da singularidade linguística dos alunos surdos, ou seja, não precisam saber Libras, mesmo essa sendo a língua de instrução de seus alunos por direito. Dessa forma, o ensino bilíngue é assegurado por lei é apenas nos anos iniciais, quando ofertado, o que não deixa de ser um "recurso para um bom adestramento" (FOUCAULT, 2000, p.143).

Dispositivo 7 - Esse dispositivo reforça o que mencionamos na lei 10436/02, pois no artigo 25 do decreto 5626/05 traz diversos pontos que elucidam um olhar terapêutico em relação a surdez e sua relação com a educação, como por exemplo: "ações de prevenção e desenvolvimento de programas de saúde auditiva; acompanhamento médico e fonoaudiólogo e terapia fonoaudiologia; atendimento em reabilitação por equipe multiprofissional" ( BRASIL, 2005, Art. 25).

Corroborando com o texto citado queremos trazer para a discussão a questão da normalidade/ anormalidade. Entendemos que ao trazer os especialistas para "tratar" da questão da surdez, estão reforçando a ideia de que esses corpos se constituam num tipo de desvio. Dessa maneira, devem ser submetidos às práticas normalizadoras. Ao permitir tal prática, criamos um assujeitamento com o intuito de controlar os surdos, que não se resume somente a sua consciência, mas em seus corpos.

Nesse sentido, percebemos que inserir conceitos como reabilitação e tratamento terapêutico, na legislação, impute-se uma estratégia de biopoder sobre os sujeitos. Para Foucault (1998a, p.80) “O corpo é uma realidade biopolítica. A medicina é uma estratégia biopolítica" (FOUCAULT, 1998a, p.80). Dessa forma, abra-se espaço para reforçar a deficiência dos sujeitos surdos ao invés de sua diferença linguística e cultural.

Outro fator que gostaríamos de ressaltar como parte do disposto, no texto do decreto, que diz "devem garantir, prioritariamente aos alunos matriculados nas redes de ensino da educação básica, a atenção integral à sua saúde" (BRASIL, 2005, art.25, grifos nossos). Ora, sendo a saúde é um serviço 
essencial a população não deveria ser priorizado um grupo em detrimento a outro. A relação estabelecida entre saúde e escola consiste em criar operadores a serviço de marcar a distinção entre normalidade e anormalidade, fixando sempre assim "quem somos 'nós' e quem são os 'outros'” (VEIGA-NETO, 2001, p.25). Vimos constante criação de dispositivos para demarcar quem são os normais e os anormais. E em decorrência disso, colocamos a escola como sendo as instituições que os abrigam. Em nosso cotidiano vemos inúmeros exemplos de como as demandas de normalidade influenciam os comportamentos da sociedade, sem que seja necessário legislar acerca de tais comportamentos.

Elencamos até aqui sete dispositivos de segurança que encontramos na legislação que reconhece e regulamenta a língua e a escolarização da pessoa com surdez, pontuando algumas técnicas usadas para normalização e controle dos surdos. Nesses dispositivos também verificamos uma sequência de pontos que se referem à normatização dessa comunidade. Com citações aos termos reabilitação e tratamentos terapêuticos relacionados à comunicação.

Ao analisarmos essa relação, verificamos que esses dispositivos estão operando tanto a tecnologia do poder quanto disciplinar, que tem como objeto a sujeição do corpo do indivíduo. Impondo normas, regras e até mesmo condições linguísticas que não pertencem à maneira que o surdo concebe o mundo. Como mencionamos, os surdos possuem uma língua diferente, e a forma como percebem o espaço é em outra perspectiva - a visual.

Nesse sentido, Souza e Gallo (2002), reforçam que essa tecnologia do biopoder, se exerce sobre um corpo coletivo, no caso em questão, a comunidade surda. Esses dispositivos vão em embate diretamente na modalidade da língua dos sujeitos surdos que se reproduz através do movimento e expressões do corpo. Impõe, de forma velada, restrições no uso, acesso, formação e direcionam a surdez para um cunho terapêutico.

Na sequência, apresentamos os setes dispositivos de segurança representados no infográfico 1 . Organizamos essa representação por compreendermos que a partir de um ponto central 'dispositivo de segurança", criam-se diversas ramificações na legislação, entretanto, sua gênese está sempre ligada na relação de poder que isola e controla um determinado grupo. 


\section{Infográfico 1: Dispositivos de segurança observados na legislação}

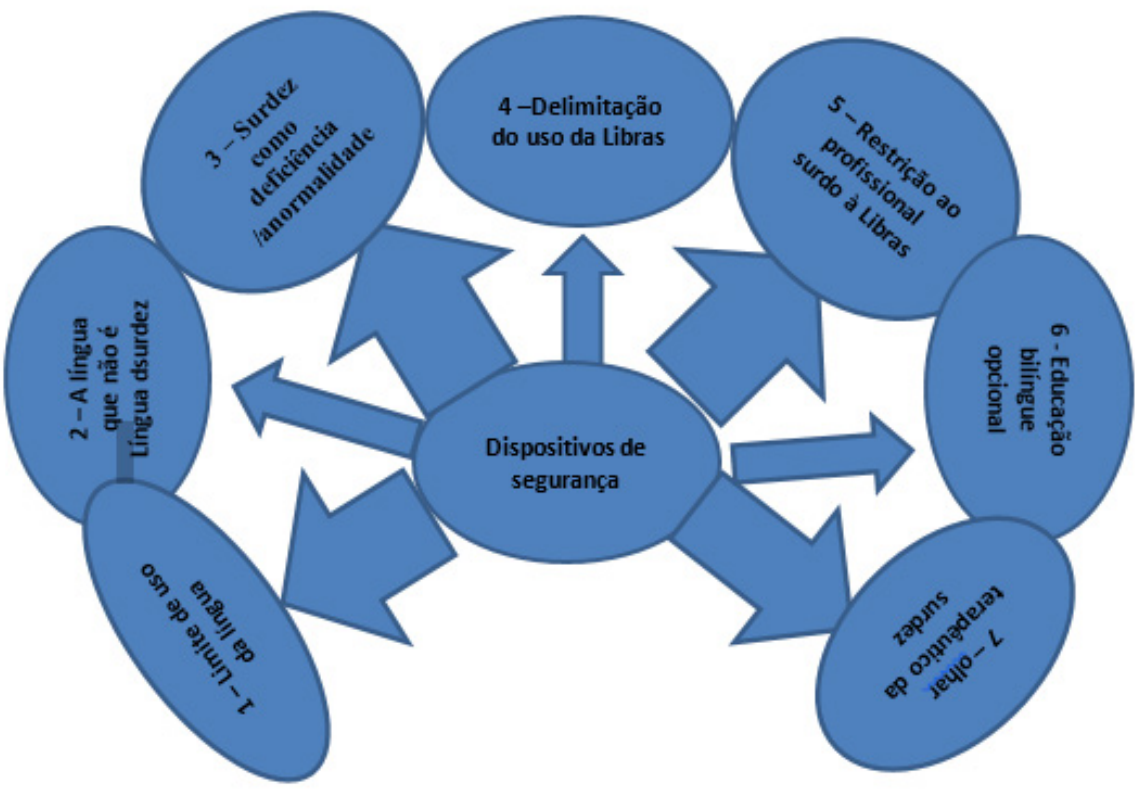

Fonte: Elaborado pelos autores, 2019.

Portanto, pautados em Foucault, estamos diante do paradoxo no qual o poder à medida que unifica seus dispositivos e, envolve os elementos da vida social de um determinado grupo, revela um novo contexto, novas possibilidades. Assim, entendemos que os dispositivos aqui apresentados oportunizam um novo contexto educacional para os surdos, talvez não da forma como a comunidade gostaria, mas fato é, que eles refletem na educação desses sujeitos, veremos alguns desses pontos na próxima sessão.

\section{Os dispositivos de segurança e seus reflexos na educação dos sujeitos surdos}

Vamos situar a nossa discussão na escola por dois motivos, o primeiro já mencionado nos dispositivos 4 e 5, revelando que a legislação reduz a participação social do surdo na educação. O segundo emerge como escopo de todos os dispositivos elencados, sendo que a instituição escolar e o fazer pedagógico como ciência corroboram para o assujeitamento das pessoas com surdez, presentes ou excluído dela. Assim, é comum que nela se criem dispositivos de segurança como forma de controle desses indivíduos. 
Para Foucault (2008) a história é descontínua, cíclica, feita de idas e vindas, com rupturas, porém, não totais. Dessa forma, é possível afirmar que, as relações de poder permeiam a educação dos surdos do início aos dias atuais, sendo marcadas por importantes conquistas, mas ainda submissa a maioria ouvinte, em um contínuo jogo de poder.

[...] as relações de poder se enraízam profundamente no nexo social; e que elas não reconstituem acima da "sociedade" uma estrutura suplementar com cuja obliteração radical pudéssemos talvez sonhar. Viver em sociedade é, de qualquer maneira, viver de modo que seja possível a alguns agirem sobre a ação dos outros. Uma sociedade "sem relações de poder" só pode ser uma abstração (FOUCAULT, 1995, p. 245-246).

Esses dispositivos de segurança que aparecem de forma sutil na legislação possibilitam interpretações das políticas públicas para o controle da a educação de estudantes com surdez. A discussão feita aqui demonstra que da forma como apresentado em nossa legislação, esses dispositivos permitem que as pessoas que desconhecem a realidade dos surdos, elabore impressões equivocados, tais como: A língua de sinais é propriedade das pessoas com surdez; o Português é a língua de instrução oficial para surdos, apesar de não ser sua língua materna; a Libras é apenas uma segunda opção e pode ser substituída; o surdo precisa de tratamento para corrigir sua deficiência de linguagem e ter uma normalidade socialmente aceita. Todas essas interpretações e outras que nos ficaram ocultas, refletem diretamente na educação, para Veiga-Neto (2001), a escola é o "locus", o lugar, em que se manifesta de maneira contundente a relação poder-saber na sociedade moderna.

Nessa perspectiva, temos dois modelos de escola, "a escola que os surdos precisam, defendida no Decreto no 5626 e a escola real oferecida aos surdos ainda são bastante diferentes" (LACERDA, 2015, p.27). Em uma leitura atenta e fundamentados em aporte teórico, entendemos que a escola foi eleita com agência de controle dos surdos, isso significa afirmar que ela compõe os espaços sociais que constituem eles enquanto sujeitos sociais. Santos e Gurgel (2015) lembram que os obstáculos que são impostos ao surdo durante sua vida escolar, são fatores que dificultam sua constituição como sujeito. Nesse sentido, Veiga-Neto vai contribuir a respeito da escola como sendo:

[...] um lugar atraente para implementar mudanças sobre essa lógica social, que se pretendam necessárias, seja no plano político, cultural ou econômico. [...]É preciso ter sempre claro que 
mesmo aquilo que parece ocorrer apenas no âmbito escolar pode ter - e, quase sempre, tem - ligações sutis e poderosas com práticas (discursivas e não-discursivas) que extravasam a própria escola. (VEIGA-NETO, 2001, p.24)

Os dispositivos de segurança podem promover forma de políticas públicas distorcidas, nesse sentido, as legislações aqui analisadas colocam na escola e, somente nela, responsabilidades sociais, como a saúde por exemplo, está legitimando o proposto por Veiga-neto (2001) quando diz que existem práticas de poder que extrapolam o espaço escolar. Os surdos vivenciam o caráter ambíguo da legislação que propõe uma educação que atendam as suas necessidades, mas com estratégias de não se obrigar a fazê-lo, ou seja, ofertamos a essa parcela da população o que eles querem, contudo colocamos formas de continuar exercendo poder sobre eles.

A proposta de educação bilíngue, que aos surdos precisam, é aquela que busca contemplar o direito linguístico da pessoa surda em ter acesso aos conhecimentos sociais e culturais em uma língua que eles não dominam. Nessa perspectiva, uma educação bilíngue precisaria envolver a criação de um ambiente para aquisição da Libras como língua materna e Português escrito como segunda língua, mas, o que nos documentos oficiais do Governo Federal é "um enorme distanciamento dos princípios do bilinguismo, [...] se efetiva o cerceamento de que as crianças se tornem membros potenciais de uma comunidade linguística viva e autônoma" (FERNANDES; MOREIRA, 2014, p. 64).

O bilinguismo, assim como alguns dos dispositivos de segurança, agem como um mecanismo legitimado pelo grupo controlado. A comunidade surda luta por muitos anos pela conquista da educação bilíngue, quando o decreto possibilita essa educação dá a eles esperança de terem conquistado tal direito. Entretanto, pós decreto surge uma série de documentos, inclusive legislações, impõe o ensino na escola regular. Lodi (2013) explica que no documento que deveria seguir orientações da lei, acabam sofrendo interpretações que mudam seus objetivos. Esse é o caso do documento de Política Nacional de Educação Especial na perspectiva inclusiva, nele não fica claro qual língua deva ser usada pelos professores nas salas de aula inclusivas. Moreira e Fernandes (2014) também tecem críticas sobre os documentos norteadores da educação especial afirmando que, nestes documentos, a Libras é considerada apenas como um recurso.

Não podemos perder de vista que como estratégia para o dispositivo em questão deixa facultativo para os anos finais do ensino fundamental a opção do ensino comum em escolas inclusivas, como já mencionamos, dando ao go- 
verno uma forma legitima e institucionalizada de poder. As formas de controle buscam sempre o padrão aceitável socialmente e estar em uma escola regular é aproximar-se da normalidade. Faz mais sentido repetir a série numa escola regular no que numa escola especial. Veiga-Neto (2001), entende a escolarização como uma operação de ordenamento, aproximação/estranhamento, ancorada na díade normal-anormal.

As questões linguísticas implícitas dos dispositivos de segurança na lei e no decreto são a expressão mais clara das medidas de controle social das quais submetem os surdos na escola. O reconhecimento da Libras como meio legal de comunicação do surdo ortogou a eles direitos, mas não estabeleceu ela como língua de instrução no espaço escolar, sem a produção de conhecimento em sua língua materna os surdos ficam resignados aos saberes ouvintes. São documentos, leis, jornais, e toda uma relação social em outra língua, com limitação de acesso e de aprendizagem, principalmente, o da língua portuguesa, configurando um ciclo que controla os surdos por gerações.

A escola inclusiva na qual os conhecimentos são produzidos e reproduzidos em Português, mesmo que tenha o intérprete de Libras, não é um espaço educacional que atende as necessidades educacionais de pessoas com surdez. Quando a língua de instrução não é a falada por todos, estão favorecendo um grupo determinado em detrimento de outro. Precisamos refletir que, nessa disputa de poder, aqueles que estão ocupando posições de liderança na escola (instituição), dão as cartas da representação, nesse caso é ouvinte.

Portanto, entendemos que o status privilegiado dado à instituição escolar, não só para os surdos, é pela sua capacidade de instituir poderes. Foucault (1998) argumenta que o poder não se esgota na negatividade, afirmando a existência de um traço positivo no poder, dizendo que ao mesmo tempo em que produz opressão, produz resistência. Nesse sentido, os surdos continuam lutando por espaços, por uma educação que atendam suas especificidades, fortalecendo a diferença e buscando formas de representatividade para alcançar autonomia e equilibrar a balança do poder.

\section{Considerações finais}

Nos propomos a identificar dispositivos de segurança nas leis que versam sobre a Língua de sinais e a educação de surdos, como forma de assujeitamento desses indivíduos. Vimos, que o meio cultural em que o deficiente está inserido é o da segregação, a sociedade como menciona Foucault (2008), assume uma postura de uma margem aceitável da deficiência e recorre a dis- 
positivos de segurança para manter o controle da população flutuante.

Pontuamos no percurso do texto que reconhecer a apropriação do mundo para pessoas com surdez se dá em outra língua se constitui em um exercício de alteridade e, esse é o caminho para uma sociedade menos desigual onde a escola se consolida como o lugar para pautar a diferença. Por isso, abordamos no processo de constituição do surdo e dos dispositivos de segurança, a questão da deficiência, as relações sociais relacionadas ao mercado profissional e a saúde, tudo a partir da instituição escolar.

É importante salientar que as leis que reconhecem, tanto no uso quanto a difusão da Libras, são grandes conquistas e possibilitaram grande avanço nas questões sobre acessibilidade linguística e educacional dos sujeitos surdos. Entretanto, o que consideramos é a forma como a legislação, de forma sutil, possibilitam práticas de políticas públicas que mantém meios de controle nas relações de poder. Procuramos não perder de vista que ao sofrer poder, os indivíduos também exercem poder, ressaltando a luta de gerações da comunidade surda pelos direitos até aqui conquistados.

Tecemos esse texto provocados por inquietações de nossas trajetórias como profissionais atuantes na comunidade surda, mas reconhecemos nossas limitações jurídicas que nos impediram de aprofundar o quanto gostaríamos em nossas proposições. Contudo, alcançamos o objetivo proposto na medida que elencamos os dispositivos de segurança, fizemos com zelo e estudo, não querendo colocar um ponto final na reflexão que fizemos nesse trabalho, mas promover um despertar para futuras pesquisas.

Enceramos citando Foucault (2008) quando ele reforça que os dispositivos de segurança "tendem perpetuamente a ampliar e novos elementos são o tempo todo integrados" (FOUCAULT 2008, p. 59), tais dispositivos vão ganhando novas características legitimadas pela própria comunidade surda, que inocente, não percebe se trata justamente de uma relação de poder onde o objetivo não é incluir, mas sim, manter o controle.

\section{Referências}

BARDIN, Laurence. Análise de conteúdo. São Paulo: Edições 70. 2011.

BRASIL. Lei no 10436 de 24 de Abril de 2002. Dispõe sobre a Língua Brasileira de Sinais - Libras e dá outras providências, 2002.

BRASIL. Decreto n 5626 de 22 de Dezembro de 2005. Que dispõe sobre a Língua Brasileira de Sinais - Libras, 2005. 
FERNANDES, Sueli; MOREIRA, Laura Ceretta. Políticas de educação bilíngue para surdos: o contexto brasileiro. Educar em Revista, Editora UFPR. Curitiba, Brasil, Edição Especial n. 2, p. 51-69, 2014.

FOUCAULT, Michel. A arqueologia do saber. Rio de Janeiro: Forense, 1986.

FOUCAULT, Michel. História da Sexualidade 1: Vontade de saber. 9ạ ed. Rio de Janeiro: Graal,1988.

FOUCAULT, Michel. Microfísica do Poder. 13a ed. Rio de Janeiro: Graal,1998a.

FOUCAULT, Michel. A Ordem do Discurso. 4a ed. São Paulo: Edições Loyola,1998b.

FOUCAULT, Michel. Vigiar e Punir. 23ạ ed. São Paulo: Editora Vozes, 2000.

FOUCAULT, Michel. Os Anormais. São Paulo: Martins Fontes, 2001.

FOUCAULT, Michel. Segurança, Território, População. Martins Fontes, São Paulo, 2008.

GUARINELLO, Ana Cristina. O papel do outro no processo de construção da produção da escrita de sujeitos surdos. 2004. 207f. Tese (Doutorado em Estudos Lingüísticos) - Programa de Pós Graduação em Letras, Universidade Federal do Paraná, Curitiba.

KARNOPP, Lodenir Becker. Práticas de leitura e escrita em escolas de surdos. In: FERNANDES, Eulalia (org.). Surdez e Bilinguismo. Porto Alegre/RS: Editora Mediação 7ạ Ed., 2015.

LACERDA, Cristina Broglia Feitosa. Intérprete de Libras: em atuação na educação infantil e no ensino fundamental. 7äEd. Porto Alegre: Mediação, 2015

LACERDA, Cristina B.F; LODI, Ana Claudia B. A inclusão escolar bilíngue de alunos surdos: princípios, breve histórico e perspectivas. IN: LODI, Ana Claudia B.; LACERDA, Cristina B.F. Uma escola, duas línguas: letramento em língua portuguesa e língua de sinais nas etapas iniciais de escolarização. 4a Ed. Porto Alegre: Mediação, 2014.

LODI, Ana Claudia Balieiro. Educação bilíngue para surdos e inclusão segundo a Política Nacional de Educação Especial e o Decreto no 5.626/05. Educ. Pesqui., São Paulo, v. 39, n. 1, p. 49-63, jan./mar. 2013.

SILVA, Rosana A. da. A Trajetória da Educação Especial Brasileira: das Propostas de Segregação à Proposta Inclusiva: O Olhar da Cidade de Mairiporã. Mo- 
nografia apresentada para conclusão do curso de Especialização Latu Sensu “A Educação Inclusiva na Deficiência Mental”, PUC, São Paulo, 2003.

SANTOS, Lara Ferreira dos; GURGEL, Taís Margutti do Amaral. O instrutor surdo em uma escola inclusiva bilíngue. IN: LODI, Ana Claudia B.; LACERDA, Cristina B.F. Uma escola, duas línguas: letramento em língua portuguesa e língua de sinais nas etapas iniciais de escolarização. 4a Ed. Porto Alegre: Mediação, 2014.

VEIGA NETO, Alfredo. Incluir para saber. Saber para excluir. Proposições: revista quadrimestral. Faculdade de Educação-UNICAMP, vol.12, São Paulo, 2001.

VEIGA NETO, Alfredo. Foucault \& a Educação. Belo Horizonte, MG, Autêntica, 2003. 